УДК 533.9

\title{
MODELLING OF THE ELECTRON CYCLOTRON RESONANCE HEATING AND CURRENT DRIVE IN THE T-15-MD TOKAMAK WITH GENRAY AND CQL3D CODES
}

\author{
P.V. Minashin ${ }^{1}$, A.B. Kukushkin ${ }^{1,2}$, R.W. Harvey ${ }^{3}$ \\ ${ }^{I}$ NRC “Kurchatov Institute”, Moscow, Russia \\ ${ }^{2}$ National Research Nuclear University MEPhI, Moscow, Russia \\ ${ }^{3}$ CompX PO Box 2672, Del Mar, CA 92014, USA \\ The simulations of the ECRH and ECCD in T-15-MD tokamak are carried out with the ray-tracing code GENRAY and the kinetic Fok- \\ ker-Planck code CQL3D for two formerly predicted regimes of tokamak operation, namely hybrid scenario with 12 MW auxiliary heat- \\ ing and 2 MA total plasma current, including inductive (Ohmic) current, and the steady-state scenario with 18 MW auxiliary heating and \\ 1 MA fully non-inductive current. The results for 2D distribution of the ECRH power density and ECCD density in the tokamak poloidal \\ cross-section on the flat-top stage of discharge are presented for various injections angles and EC wave modes. It is shown that for the \\ ECCD in the hybrid scenario the injection of the X2-wave from the LFS is more effective than injection of the X1-wave from the HFS.
}

Key words: electron cyclotron waves, tokamak, auxiliary heating of plasma, generation of electric current.

\section{МОДЕЛИРОВАНИЕ ЭЛЕКТРОННОГО ЦИКЛОТРОННОГО РЕЗОНАНСНОГО НАГРЕВА И ГЕНЕРАЦИИ ТОКА В ТОКАМАКЕ Т-15-МД С ПОМОЩЬЮ КОДОВ GENRAY И CQL3D}

\author{
П.В. Минашин ${ }^{1}$, А.Б. Кукушкинн ${ }^{1,2}$, Р.В. Харви ${ }^{3}$
}

\author{
${ }^{1}$ НИЦ «Курчатовский институт», Москва, Россия \\ ${ }^{2}$ Национальный исследовательский ядерный университет «МИФИ», Москва, Россия \\ ${ }^{3}$ CompX PO Box 2672, Del Mar, CA 92014, USA
}

Проведены расчёты ЭЦ-нагрева и ЭЦ-генерации тока в токамаке T-15-МД с помощью лучевого кода GENRAY и кинетического фоккер-планковского кода CQL3D для двух ранее предсказанных режимов работы токамака, а именно гибридного сценария с мощностью дополнительного нагрева 12 МВт и полным током в плазме 2 МА, включая индуктивный (омический) ток, и стационарного сценария с мощностью дополнительного нагрева 18 МВт и полностью неиндуктивным током в плазме 1 МА. Результаты для двумерных распределений плотности мощности ЭЦ-нагрева и плотности ЭЦ-тока в полоидальном сечении токамака на квазистационарной стадии разряда представлены для различных углов инжекции и разных мод ЭЦ-волны. Показано, что для ЭЦ-генерации тока в гибридном сценарии инжекция Х2-волны со стороны слабого магнитного поля является более эффективной, чем инжекция Х1-волны со стороны сильного поля.

Ключевые слова: электронные циклотронные волны, токамак, дополнительный нагрев плазмы, генерация электрического тока.

DOI: 10.21517/0202-3822-2016-39-3-65-72

\section{INTRODUCTION}

Electron cyclotron resonance heating (ECRH) is a well-proven tool for the additional plasma heating by the high frequency EM-waves used in many operating tokamaks and stellarators (see, e.g., review [1]). Launched radio-frequency waves have strong resonance interaction with the plasma electrons (having cyclotron frequency close to the frequency of the injected waves), which leads together with the space dependent magnetic field in a fusion device to the high localization of the absorbed power deposition. In addition, these properties of the EC radiation allow for effective generation of the non-inductive current drive (ECCD).

Recent predictive modelling [2] of the operating steady-state scenarios of the T-15-MD tokamak show the need for up to $15 \mathrm{MW}$ of the auxiliary plasma heating. Planned ECRH system of the T-15-MD tokamak will perform following functionalities:

- microwave breakdown; 
— neoclassical tearing mode stabilization;

- ELM stabilization;

- non-inductive current drive.

The expanded range of ECRH applications makes it necessary to perform extensive optimization studies of the EM-wave launchers parameters. Here we perform simulations of the ECRH and ECCD in two scenarios of the T-15-MD tokamak operation.

The main tools used in this work for modelling of the ECRH and ECCD are the ray-tracing code GENRAY [3] and the kinetic Fokker-Planck code CQL3D [4]. Both codes are widely used for interpreting results of the ECRH experiments in various operating fusion devices and for predictive modelling of ECRH and ECCD in the next-step devices, e.g. tokamak ITER (see the reviews $[1,5]$ and particular cases $[6,7]$ ).

The GENRAY ray-tracing code calculates propagation (in the geometrical optics approximation) of the injected EM-waves and the absorption of the wave power along the wave trajectory in the plasma, using semi analytical models [5] for both of the kinetic processes ECRH and ECCD. The CQL3D code is a general-purpose computer code for modeling auxiliary heating in tokamaks. It calculates the radial distribution of $2 \mathrm{D}$, in momentum-space, bounceaveraged, ion and electron distribution functions in toroidal geometry, consistent with deposition of radio-frequency (RF) and/or neutral beam injected power. This calculation may be carried out with an array of bounce-averaged Fokker-Planck solvers running on noncircular magnetic flux surfaces, giving the steady-state, toroidally-averaged distribution resulting from a balance between collisions, direct current (DC) electric field, RF quasilinear diffusion, synchrotron radiation, neutral beam injection, and radial diffusion. The CQL3D code is coupled to ray-tracing code GENRAY for electron cyclotron, lower hybrid, and fast waves, to a neutral beam deposition code, and to a noncircular equilibrium.

The calculations with the CQL3D + GENRAY codes here are performed for two scenarios of the T-15-MD tokamak operation (steady-state scenario with fully non-inductive plasma current and hybrid scenario, when external current drive systems and the bootstrap current provide a substantial fraction, but not all, of the total plasma current) for two different EM-wave injection geometries (from equatorial port on the low magnetic field side and from the upper port on the high magnetic field side).

\section{BASIC SCENARIOS OF THE T-15-MD TOKAMAK}

The T-15-MD tokamak is planned as a warm magnetic-coils tokamak with the flexible ITER-like configuration of magnetic field, which makes it possible to obtain the form of plasma column with the high aspect ratio in the range 2.2-3.0, with the non-inductive current drive and the long pulse [8]. The base parameters of the T-15-MD tokamak:

$\begin{array}{ll}\text { Toroidal magnetic field on the torus axis } B_{0}, \mathrm{~T} \ldots & 2.0 \\ \text { Plasma current } I_{\mathrm{p}}, \mathrm{MA} \ldots & 2 \\ \text { Major torus radius } R_{0}, \mathrm{~m} \ldots & 1.48 \\ \text { Minor torus radius } a, \mathrm{~m} \ldots & 0.67 \\ \text { Aspect ratio } A \ldots & 2.2-3.0 \\ \text { Elongation } k_{\mathrm{elong}} \ldots & 1.7-1.9 \\ \text { Triangularity } \delta \ldots & 0.3-0.4 \\ \text { Density limit } n_{e}, 10^{20} \mathrm{~m}^{-3} \ldots & 1.4 \\ \text { Effective charge } Z_{\mathrm{eff}} \ldots & 1.6\end{array}$

Recent analysis [2] of the T-15-MD tokamak operation regimes (calculations carried out with the ASTRA transport code [9]) show the possibility of the two basic scenarios: the inductive scenario with the $\sim 4 \mathrm{~s}$ plasma discharge (and $\sim 1 \mathrm{~s}$ duration of current plateau) and the hybrid scenario with $12 \mathrm{MW}$ auxiliary heating (6 MW NBI + $+6 \mathrm{MW} \mathrm{ECRH}$ ) with the increased to $10 \mathrm{~s}$ duration of the current plateau for the same value of the nominal plasma current $I_{\mathrm{p}}=2 \mathrm{MA}$. It is also considered steady-state scenario with $18 \mathrm{MW}$ auxiliary heating $(6 \mathrm{MW} \mathrm{NBI}+$ + $5 \mathrm{MW}$ ECRH + $7 \mathrm{MW}$ RF power) with higher value of plasma discharge duration $~ 20 \mathrm{~s}$, increased density, with fully non-inductive plasma current $I_{\mathrm{p}}=1 \mathrm{MA}$ and on-axis toroidal magnetic field $B_{0}=1.5 \mathrm{~T}$. Spatial profiles (as a 
function of the square root of the normalized toroidal magnetic flux, $\rho$ ) of the main plasma parameters for considered scenarios with and without inductive current are shown in Fig. 1 and Fig. 2, respectively.
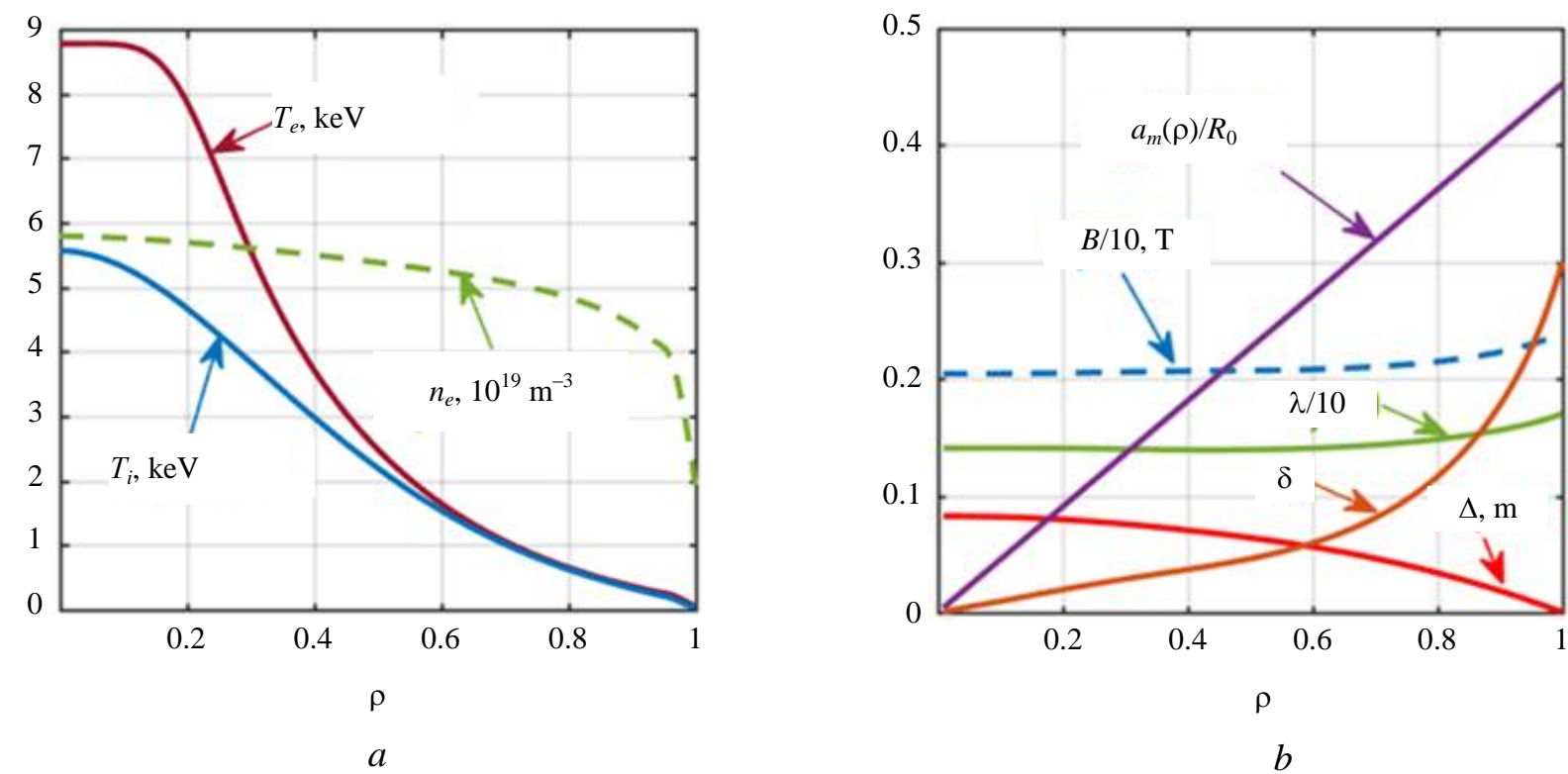

Fig. 1. Spatial profiles of the main plasma parameters for the hybrid scenario of the T-15-MD tokamak operation with 12 MW auxiliary heating and $I_{\mathrm{p}}=2 \mathrm{MA}$ : electron and ion temperatures and electron density profiles as a function of the magnetic surface label $\rho$ (square root of the normalized toroidal magnetic flux) $(a)$; 1D profile of the total magnetic field and parameters of the magnetic surfaces: Shafranov shift $\Delta(\rho)$, triangularity $\delta(\rho)$, elongation $\lambda(\rho)\left(\lambda(1) \equiv k_{\text {elong }}\right)$, and the magnetic surface minor radius in the mid-plane $a_{\mathrm{m}}(\rho)(b)$. The magnetic equilibrium was calculated with the 3 -moment equilibrium solver in the ASTRA code
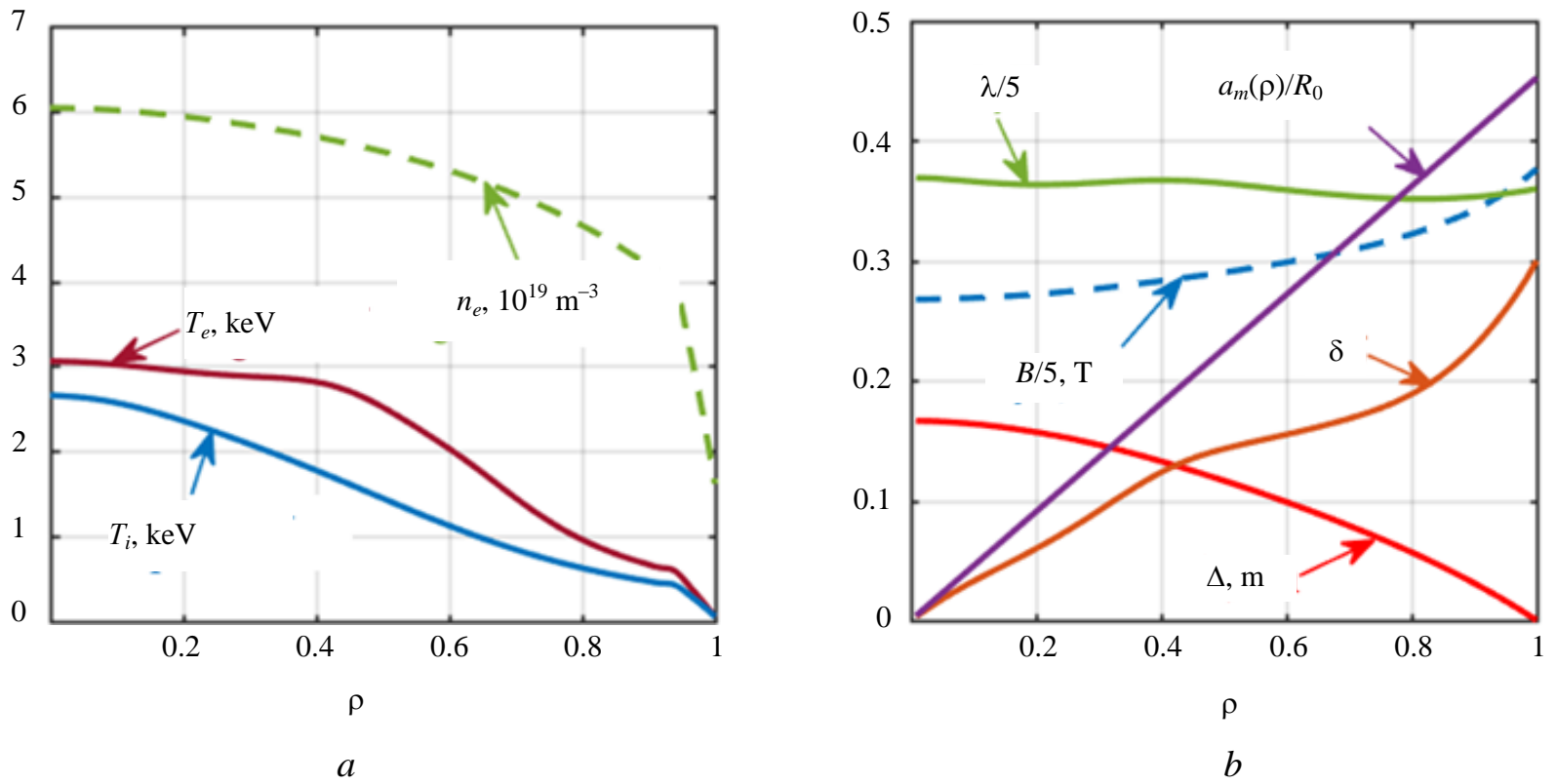

Fig. 2. The same as in Fig. 1 but for the steady-state scenario of T-15-MD tokamak operation with 18 MW auxiliary heating, fully noninductive current $I_{\mathrm{p}}=1 \mathrm{MA}$, and $B_{0}=1.5 \mathrm{~T}$

\section{EC-WAVE PROPAGATION AND ACCESSIBILITY, LAUNCH GEOMETRY}

The EC system planned on the T-15-MD tokamak consists of gyrotrons with frequency $v=56 / 112 \mathrm{GHz}$ (extraordinary fundamental harmonic X1- and second harmonic X2-wave, resonance magnetic field on axis $B_{0}=2 \mathrm{~T}$ ) 
and $v=82 \mathrm{GHz}$ (X2-wave, resonance magnetic field on axis $B_{0}=1.5 \mathrm{~T}$ ). Here only the case $v=56 / 112 \mathrm{GHz}$ is considered. The bounds of the EC-wave propagation regions in T-15-MD tokamak are shown in Fig. 3. Fig. 4 presents a schematic view of the EC-wave launching system.


Fig. 3. EC-wave cutoffs and resonances propagation and accessibility of the O1-wave (green zones), red zones show the regions where propagation of the $\mathrm{O}$-wave is not allowed, $v_{\mathrm{c} 0}$ is the fundamental $\mathrm{EC}$-wave frequency for the resonance magnetic field on axis $B_{0}=2 \mathrm{~T}$ : $v_{\mathrm{p}}$ is the plasma frequency cutoff for the $\mathrm{O}$-wave $(a)$; the same as $(a)$ but for the $\mathrm{X}$-wave, $v_{\mathrm{UH}}$ is the upper hybrid resonance, $v_{\mathrm{R}}$ and $v_{\mathrm{L}}$ are cutoffs for the right-hand and the left-hand polarized waves, respectively $(b)$

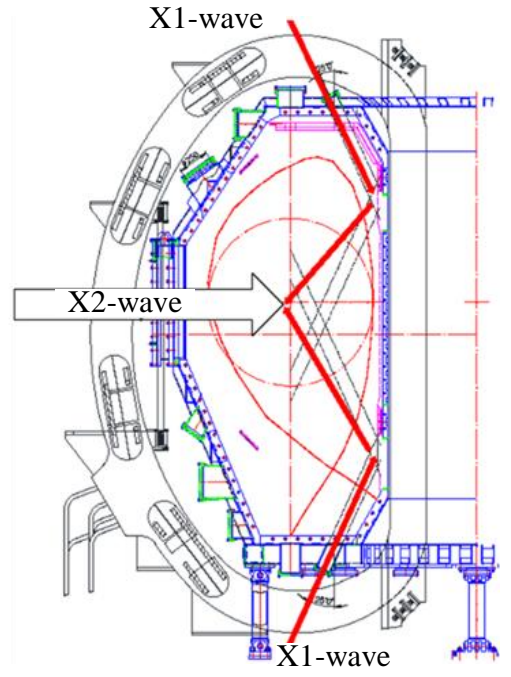

Fig. 4. View of the EC launching scheme in the poloidal cross-sections of the T-15-MD tokamak



The existence of the cutoff density limits the application of EC-waves to plasma. Fig. 3 shows that for the T-15-MD tokamak the fundamental ordinary O1-wave has a density propagation limit (cutoff) less than the planned operating T-15-MD plasma density. X1- and X2-waves have the propagation density limits up to twice more than O1-wave density limit. The fundamental resonance for the X1-wave is not accessible from the low magnetic field side because of the right-hand cutoff, so the X1-waves must be launched from the high magnetic field side of the plasma (see Fig. 4). Launching X1-wave from the high magnetic field side usually leads to a number of technical difficulties in tokamaks [1]. Therefore for the intermediate field tokamaks (like ASDEX Upgrade, DIII-D) to overcome O1-wave limitations and the X1-wave launching difficulties the $\mathrm{X} 2$-wave is used.

The trajectories of the EC-waves can be calculated with the ray-tracing codes. The launcher injection angles (Fig. 5) determine the initial direction of EM-waves, the further propagation of EM-waves in plasma is described in the geometrical optics approximation.

b

$c$

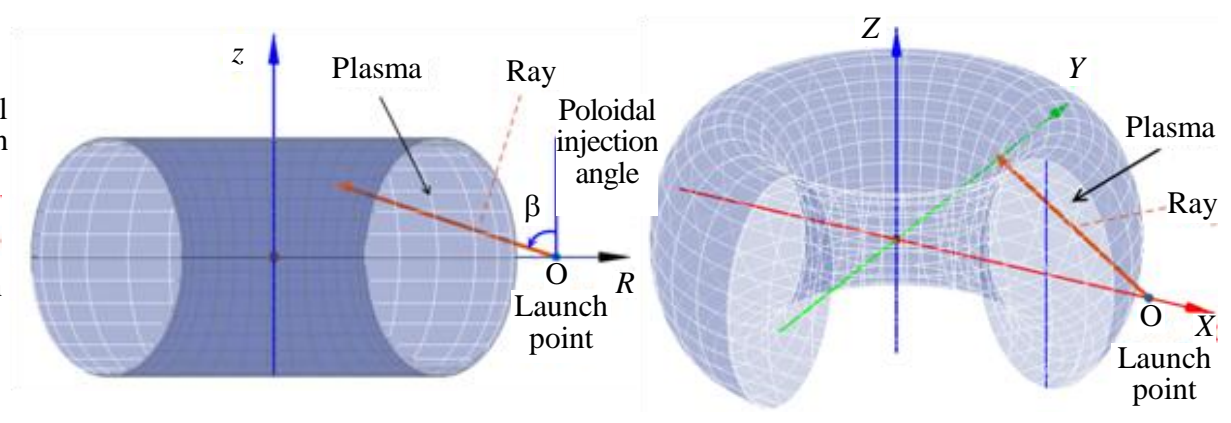

Fig. 5. The definition of launching injection angles: tokamak cross-section in equatorial plane $(X, Y)$, toroidal injection angle, $\alpha(a)$; cross-section view in the poloidal plane $(R, Z)$, the poloidal injection angle $\beta(b)$; 3D view $(c)$ 
The calculations for both a single ray and a beam with 30 rays are performed with the GENRAY code. All EC-wave trajectories for performed scan over injection angle are shown in Fig. 6-8.
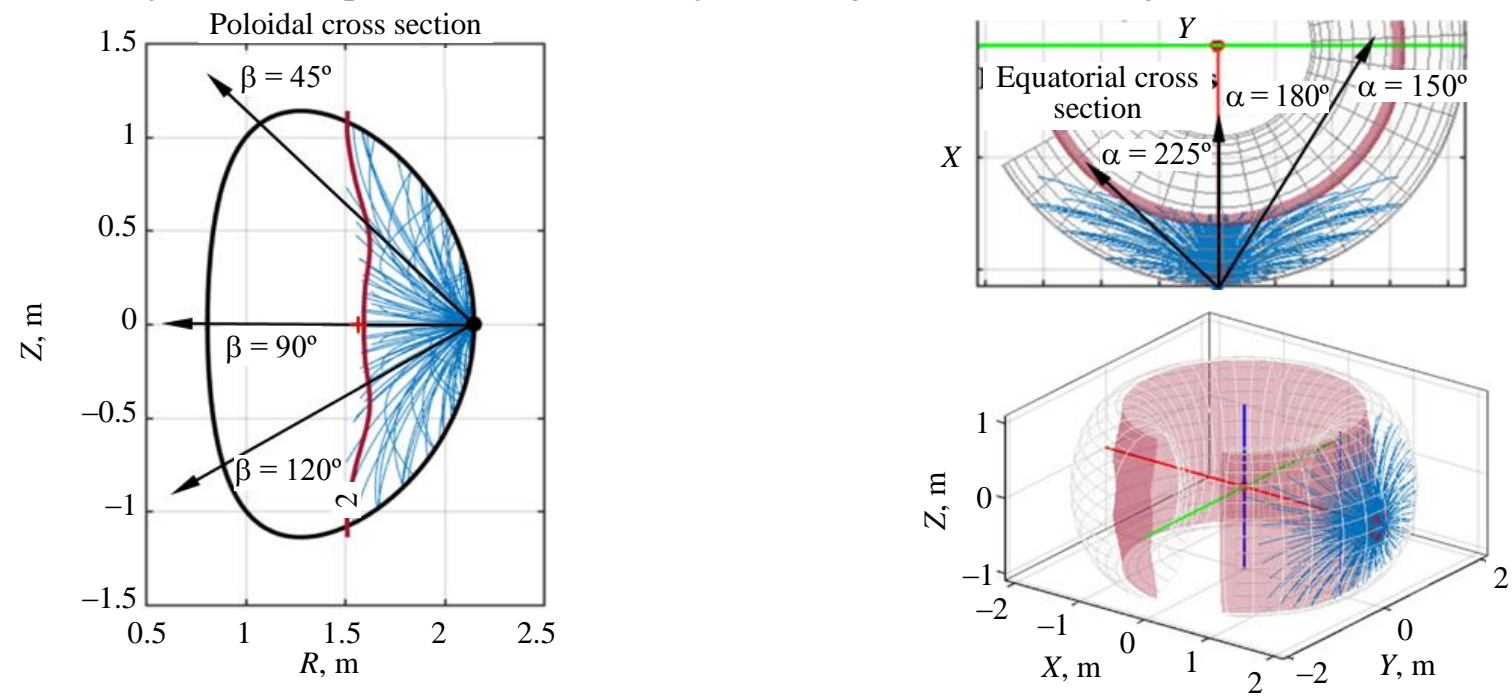

Fig. 6. X2-wave launch in hybrid scenario of T-15-MD tokamak with inductive current (cf. Fig. 1). Trajectories of the all EC-waves for various injection angles are shown, red line corresponds to 2nd harmonic of EC-frequency with respect to gyrotron frequency
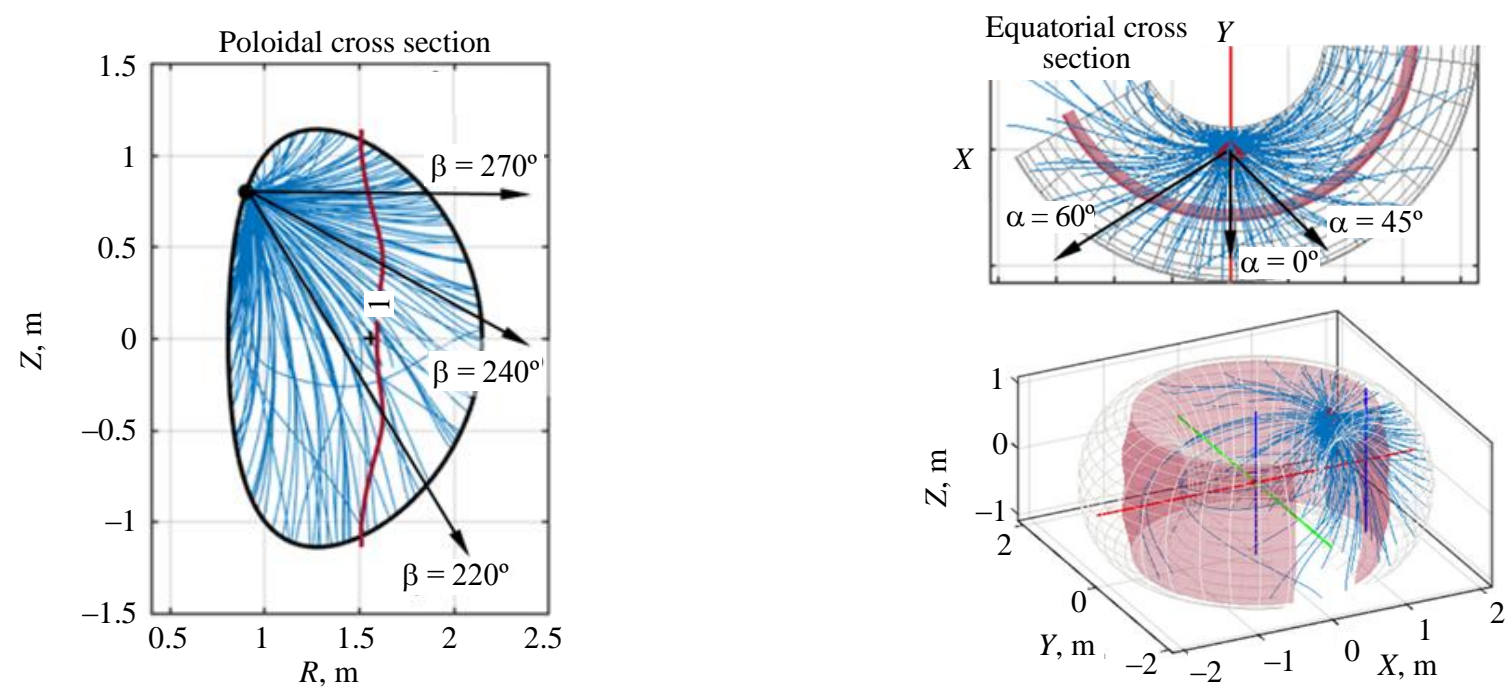

Fig. 7. The same as in Fig. 6 but for the X1-wave launch, red line corresponds to 1st harmonic of EC-frequency with respect to gyrotron frequency
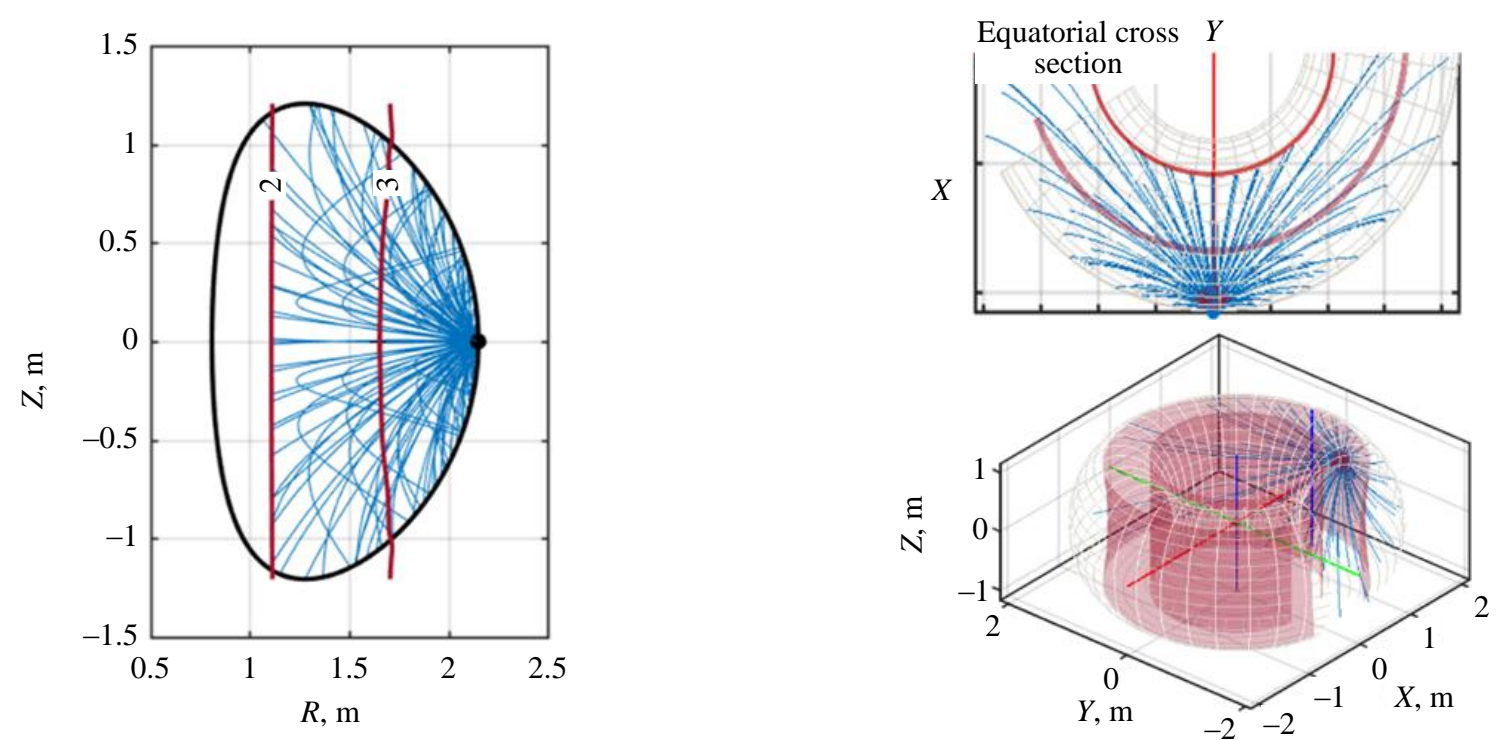

Fig. 8. The same as in Fig. 6 but for the X2-wave launch in steady-state scenario with $18 \mathrm{MW}$ auxiliary heating and fully non-inductive current $I_{\mathrm{p}}=1 \mathrm{MA}$ (cf. Fig. 2), red lines correspond to 2nd and 3rd harmonics of EC-frequency with respect to gyrotron frequency 


\section{ECRH AND ECCD IN T-15-MD TOKAMAK}

Modelling of the ECRH and ECCD is performed with the CQL3D code coupled with the GENRAY raytracing calculations (see Figs. 6-8).The crucial quantities in the ECRH and ECCD physics are the EC wave absorption location (Fig. 9), the ratio of the absorbed EC-wave power to the total injected wave power (Fig. 10), the ECCD efficiency (Fig. 11) and the EC current density profile (Fig. 12). The current drive efficiency is characterized by the dimensionless quantity $\zeta_{\mathrm{EC}}$, defined as follows:

$$
\zeta_{\mathrm{EC}}=\frac{e^{3} n_{e} I_{\mathrm{EC}} R}{\varepsilon_{0}^{2} P_{\mathrm{EC}} k T_{e}} \approx 32.7 \frac{n_{e}\left[10^{20} \mathrm{~m}^{-3}\right] I_{\mathrm{EC}}[\mathrm{A}] R[\mathrm{~m}]}{P_{\mathrm{EC}}[\mathrm{W}] T_{e}[\mathrm{keV}]},
$$

where $n_{e}$ is the volume-average density in units of $10^{20} \mathrm{~m}^{-3}, I_{\mathrm{EC}}$ is the total driven current in A, $R$ is the tokamak major radius in meters, $P_{\mathrm{EC}}$ is the total absorbed EC power in W, and $T_{e}$ is the volume-average temperature in $\mathrm{keV}$.
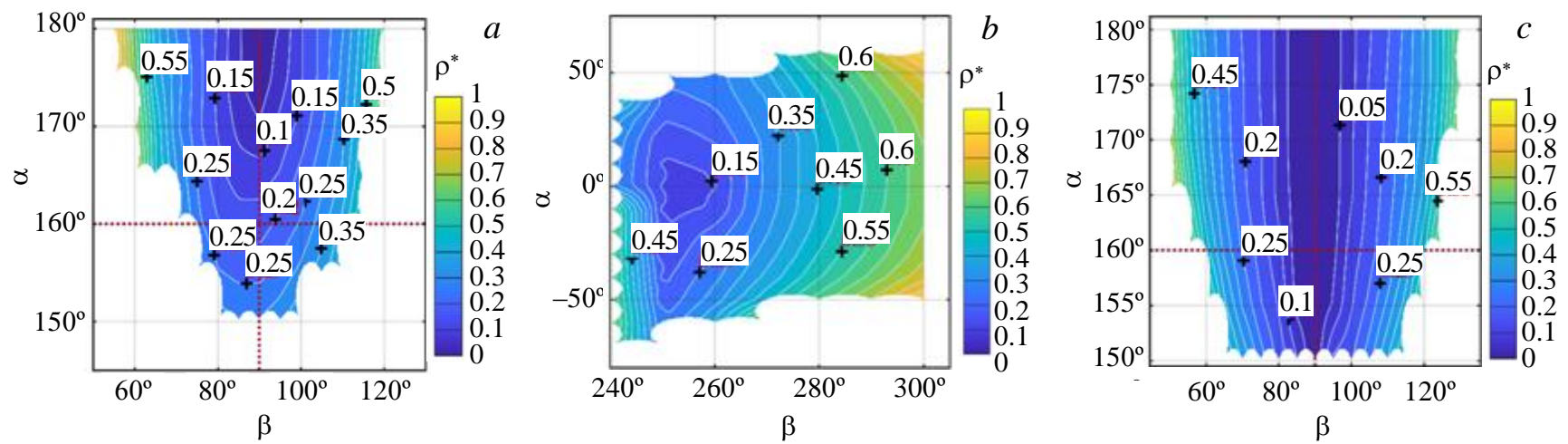

Fig. 9. The coordinate of the EC-wave absorption maximum, $\rho^{*}$ (the label of the magnetic surface), for various wave injection angles: poloidal angle $\beta$ and toroidal angle $\alpha$; X2-wave launch scheme in hybrid scenario of tokamak T-15-MD (Fig. 1) with 12 MW auxiliary heating and plasma current $I_{\mathrm{p}}=2 \mathrm{MA}$, including the inductive current $(a)$; X1-wave launch in hybrid scenario $(b)$; X2-wave ECH in steady-state scenario with $18 \mathrm{MW}$ auxiliary heating and fully non-inductive plasma current $I_{\mathrm{p}}=1 \mathrm{MA}(\mathrm{c})$
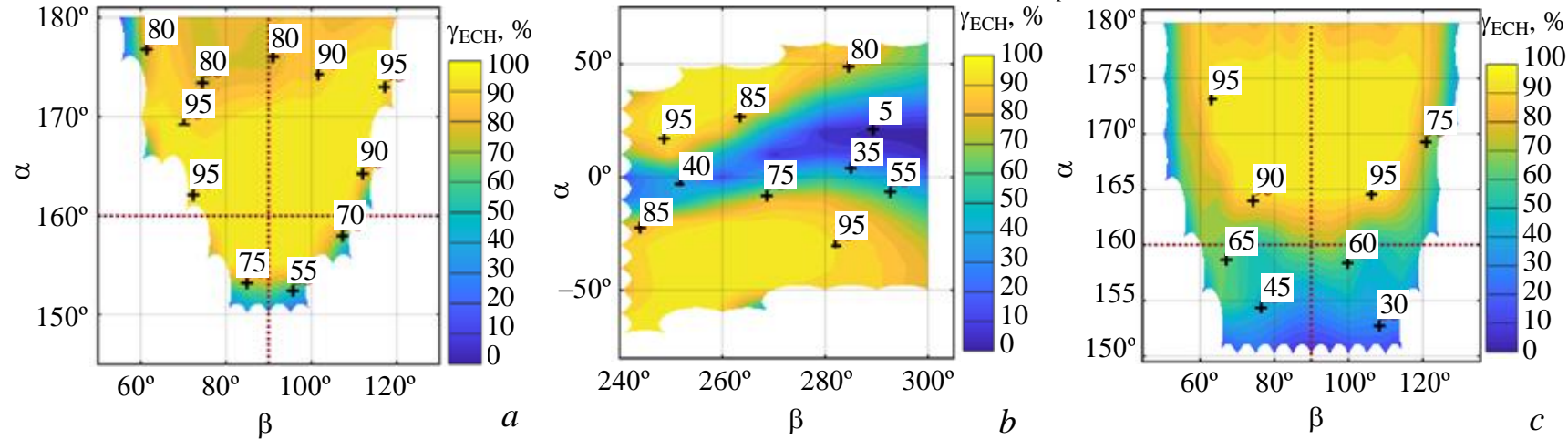

Fig. 10. The ratio of the absorbed wave power to the total injected power for various wave injection angles: poloidal angle $\beta$ and toroidal angle $\alpha$ : X2-wave launch scheme in hybrid scenario of tokamak T-15-MD (Fig. 1) with $12 \mathrm{MW}$ auxiliary heating and plasma current $I_{\mathrm{p}}=2 \mathrm{MA}(a)$; X1-wave launch in hybrid scenario $(b)$; X2-wave ECH in steady-state scenario with $18 \mathrm{MW}$ auxiliary heating and fully non-inductive plasma current $I_{\mathrm{p}}=1 \mathrm{MA}(c)$


Fig. 11. The dimensionless ECCD efficiency for various wave injection angles: poloidal angle $\beta$ and toroidal angle $\alpha$ : X2-wave launch scheme in hybrid scenario of tokamak T-15-MD (Fig. 1) with $12 \mathrm{MW}$ auxiliary heating and plasma current $I_{\mathrm{p}}=2 \mathrm{MA}$ (with maximum EC driven current equal to $0.4 \mathrm{MA})(a)$; X1-wave launch in hybrid scenario (negligible EC driven current $<1 \mathrm{kA})(b)$; X2-wave ECH in steady-state scenario with $18 \mathrm{MW}$ auxiliary heating and fully non-inductive plasma current $I_{\mathrm{p}}=1 \mathrm{MA}$ (with maximum EC driven current equal to $\left.0.09 \mathrm{MA}\right)(c)$ 




Fig. 12. Spatial profile of the EC driven current for X2-wave launch scheme in hybrid scenario of tokamak T-15-MD (Fig. 1) with $12 \mathrm{MW}$ auxiliary heating and plasma current $I_{\mathrm{p}}=2 \mathrm{MA}$ (maximum EC driven current equal to $0.4 \mathrm{MA}$ ): $1-\alpha=170^{\circ}, \beta=85^{\circ}, I_{\mathrm{EC}}=-0.3 \mathrm{MA}$; $2-\alpha=165^{\circ}, \beta=85^{\circ}, I_{\mathrm{EC}}=-0.4 \mathrm{MA} ; 3-\alpha=170^{\circ}, \beta=95^{\circ}$ $I_{\mathrm{EC}}=-0.3 \mathrm{MA} ; 4-\alpha=165^{\circ}, \beta=80^{\circ}, I_{\mathrm{EC}}=-0.3 \mathrm{MA} ; 5-\alpha=165^{\circ}$, $\beta=100^{\circ}, I_{\mathrm{EC}}=-0.3 \mathrm{MA} ; 6-\alpha=155^{\circ}, \beta=90^{\circ}, I_{\mathrm{EC}}=-0.3 \mathrm{MA}$

ting DIII-D tokamak, because of the large similarity of these machines (DIII-D parameters are as follows: major radius $R=1.7 \mathrm{~m}$, minor radius $a=0.6 \mathrm{~m}$, elongation $k=1.8$, toroidal magnetic field $B=1.65-2.15 \mathrm{~T}$, and total plasma current $I_{\mathrm{p}}=0.6-1.3 \mathrm{MA}$ ). On DIII-D, the ECCD experiments were carried out [10] to validate the predictive model for ECCD, implemented in CQL3D code. The experimental ECCD efficiency was found to be in a good agreement with the CQL3D calculations. For the X2-wave ECCD in DIII-D tokamak with $\beta_{e}=0.2 \%$, EC-wave absorption maximum at $\rho^{*}=0.4$, parallel refractive index $N_{\|}= \pm 0.4$ and poloidal injection angle equal to $135^{\circ}$ the value of the dimensionless efficiency is 0.2 , which is close to the calculated values of $\zeta_{\mathrm{EC}}$ for T-15-MD tokamak (Fig. 11,a).

We have to note that in the "heat-pinch" experiments on the DIII-D tokamak a strong conversion of the HFS-injected X1-wave of the EC-wave into the electronic Bernstein wave (EBW) was found (see Fig. 1 in [11]). Estimation of similar absorption mechanism in the T-15-MD tokamak shows that for the hybrid scenario the conditions for such an absorption are not fulfilled. However, for the steady-state scenario, further analysis is needed.

\section{CONCLUSIONS}

The simulations of the ECRH and ECCD in T-15-MD tokamak are carried out with the ray-tracing code GENRAY [3] and the kinetic Fokker-Planck code CQL3D [4] for two formerly predicted [2] regimes of tokamak operation, namely hybrid scenario with $12 \mathrm{MW}$ auxiliary heating and $2 \mathrm{MA}$ total plasma current, inclu-ding inductive (Ohmic) current, and the steady-state scenario with $18 \mathrm{MW}$ auxiliary heating and $1 \mathrm{MA}$ fully non-inductive current. The results for 2D distribution of the ECRH power density and ECCD density in the tokamak poloidal cross-section on the flat-top stage of discharge are presented. The simulations are carried out for two cases of wave launching geometry: from equatorial port-plug at the low magnetic field side (LFS) and from the upper port-plug with mirror reflections to launch the wave from the high magnetic field side (HFS). A scan over injection angles is made within the range allowed by the geometry of the facility. The above enables us to produce a database for the following parameters: 2D spatial profiles of the ECRH power density, 2D spatial profiles of EC driven current density, and integral dimensionless efficiency of the ECCD. It is shown that for the ECCD in the hybrid scenario, the injection of the X2-wave from the LFS is more effective than injection of the X1-wave from the HFS. 
Acknowledgements. The authors are grateful to N.A. Kirneva, I.N. Roy, and P.P. Khvostenko for providing the data on the T-15-MD design and physics tasks, and V.M. Leonov, for providing the data of simulations [2]. Helpful comments from N.A. Kirneva are highly appreciated.

\section{REFERENCES}

1. Prater R. Heating and current drive by electron cyclotron waves. - Physics of Plasmas, 2004, vol. 11, pp. 2349-2376.

2. Leonov V.M. Study of conditions for obtaining quasi-stationary regimes in T-15-MD tokamak. - Problems of Atomic Science and Technology. Ser. Thermonuclear Fusion, 2016, vol. 30, p. 73.

3. Smirnov A.P., Harvey R.W., Kupfer K. A general ray tracing code GENRAY. - Bulletin of the American Physical Society, 1994, vol. 39, p. 1626.

4. Harvey R.W., McCoy M.G. - In: Proc. of the IAEA Technical Committee Meeting on Advances in Simulation and Modeling of Thermonuclear Plasmas. Montreal, Canada, IAEA Institute of Physics Publishing, 1992, pp. 489-526.

5. Prater R., Farina D., Gribov Y., Harvey R.W. et al. Benchmarking of codes for electron cyclotron heating and electron cyclotron current drive under ITER conditions. - Nuclear Fusion, 2008, vol. 48, p. 035006.

6. Harvey R.W., Perkins F.W. Comparison of optimized ECCD for different launch locations in a next step tokamak reactor plasma. - Nuclear Fusion, 2001, vol. 41, p. 1847.

7. Harvey R.W., Nevins W.M., Smith G.R., Lloyd B. et al. Electron cyclotron heating and current drive in ITER. - Nuclear Fusion, 1997, vol. 37, p. 69.

8. Azizov E., Belyakov V., Filatov O., Velikhov E. et al. - In: Proc. of the 23rd IAEA Fusion Energy Conference. Daejeon, South Korea, 2010, FTP/P6-01.

9. Pereverzev G.V., Yushmanov P.N. - Report Max-Planck-Institut für Plasmaphysik, IPP 5/98, 2002.

10.Petty C.C., Prater R., Lohr J., Luce T.C. et al. - Report United States. Department of Energy, GAA23977, 2002.

11.Forest C.B., Harvey R.W., Smirnov A.P. Power deposition by mode converted electron Bernstein waves in the DIII-D "heat pinch" experiments. — Nuclear Fusion, 2001, vol. 41, p. 619.

\section{AUTHORS}

Minashin P.V. NRC "Kurchatov Institute", pl. Akademika Kurchatova 1, 123182 Moscow, Russia; Minashin_PV@nrcki.ru

Kukushkin A.B. NRC "Kurchatov Institute", pl. Akademika Kurchatova 1, 123182 Moscow, Russia; Kukushkin_AB@nrcki.ru

Harvey R.W. Computational Modeling and Software Development (CompX SM) P.O. Box 2672; bobh@compxco.com 